\title{
Modelling erosion development during wave overtopping of an asphalt road covered dike
}

\author{
Anouk Bomers ${ }^{1, a}$, Juan P. Aguilar ${ }^{1}$, Jord J. Warmink ${ }^{1}$ and Suzanne J.M.H. Hulscher ${ }^{1}$ \\ ${ }^{1}$ University of Twente, Department Water Engineering and Management, 7500 AE Enschede, The Netherlands
}

\begin{abstract}
Wave overtopping initiates erosion of dikes, thereby compromising the safety against flooding. Structures integrated in a grass covered dike may decrease the resistance against erosion. In this study, CFD modelling is used to assess the effect of an asphalt road on top of the dike crest on the initiation of erosion due to wave overtopping. The Reynolds-Averaged Navier-Stokes equations are solved via a k- $\varepsilon$ turbulence model. Two wave overtopping experiments are used for validating the hydrodynamics and the coupled hydrodynamic-erosion model. The amount of scour caused by overtopping waves is predicted by combining the shear stresses from the CFD model with an erosion model including grass erosion. Both the hydrodynamics and scour depths show good agreement with the measurements. Results show that a dike profile with a road on top of the crest is more vulnerable to erosion development than a bare grass covered dike profile. This is caused by a combination of the smoother asphalt section and the damaged berms at the transitions of the asphalt with the grass cover.
\end{abstract}

\section{Introduction}

Many coastal and riverine areas are protected against floods by earthen dikes. Due to climate change, the sea level rises and peak river discharges increase. This requires more robust flood defences [1]. Wave overtopping is one of the main causes of dike breaches and has frequently occurred in the past [2]. If waves overtop the dike crest, they run down on the inner slope and may cause erosion of the this slope, which can ultimately result in dike breach.

Laboratory experiments have been performed to understand breaching processes and to collect reliable data to develop breach models [3]. Erosion of a dike with a homogeneous cover starts at the centre of the inner dike slope and evolves towards the toe (e.g. [4], [5]). The soil properties highly influence the timing and rates of the observed erosion process [6].

Many dikes consist of a grass sod with a clay layer of 50 till 70 centimetres thickness and a sandy core [7]. Dike breach of such a dike profile evolves slower compared to a homogeneous sand dike. First the grass sod is eroded. This starts with washing out of small particles from the underlying soil under flow action. The grass is teared off when the roots that are close to the soil surface are exposed to the flow by the erosion process [8]. Erosion of the underlying clay layer continues due to headcut erosion and finally the core of the dike is washed out. For a dike that consists of one cover material, erosion starts to occur close to the toe of the dike. This induces steepening of the slope in time and gradually evolves into a headcut [9].
[10] showed experimentally that erosion started at disturbances in the dike profile and near objects. Erosion may develop due to water run off being focused at the transition between the materials, and by local flow turbulence caused by structure geometry or roughness variations [11]. However, little is known on the influence of dike objects on the erosion development during wave overtopping.

A large number of flood defences have roads located at the crest. The exact influences of a road structure on surface erosion patterns and on the safety level of a dike are not yet known. Structures inside and on top of a flood defence may lead to earlier or later dike failure. Earlier dike failure can have large economic and environmental consequences. Therefore, research on the effect of structures on the safety level of a dike is important.

The objective of this study is to quantify the influence of a road structure on the onset of erosion of a dike with a grass cover due to wave overtopping. The study mainly focuses on the effect of transitions between the grass sod and the asphalt road.

The objective is reached using a coupled hydrodynamic-erosion model. A 2DV unsteady Computation Fluid Dynamics (CFD) simulation is performed and the outcomes are used to compute the amount of scour and the erosion profile. The outline of this paper is as follows. Chapter 2 presents the data used for validation. Chapter 3 describes the coupled hydrodynamic-erosion model. Chapter 4 and 5 gives the results and discussion respectively. The paper ends with the main conclusions provided in Chapter 6 .

\footnotetext{
${ }^{a}$ Corresponding author: a.bomers@utwente.nl
} 


\section{Validation data}

We use data from two wave overtopping experiments performed in Millingen aan de Rijn in order to validate the CFD model and the newly developed coupled hydrodynamic-erosion model. In particular, we use data of a river dike, but the results apply to a wide range of dike types. The experiments in Millingen aan de Rijn were performed to investigate the influence of an asphalt road located on top of the crest of a dike.

The experiments were carried out using the wave overtopping simulator [10]. The wave overtopping simulator consists of a mobile box to store water (Fig. 1). Various overtopping volumes were released following a stochastic random process in order to simulate a realistic overtopping event [5]. The water was released on the outer side of the crest and ran over the crest and down the inner slope.
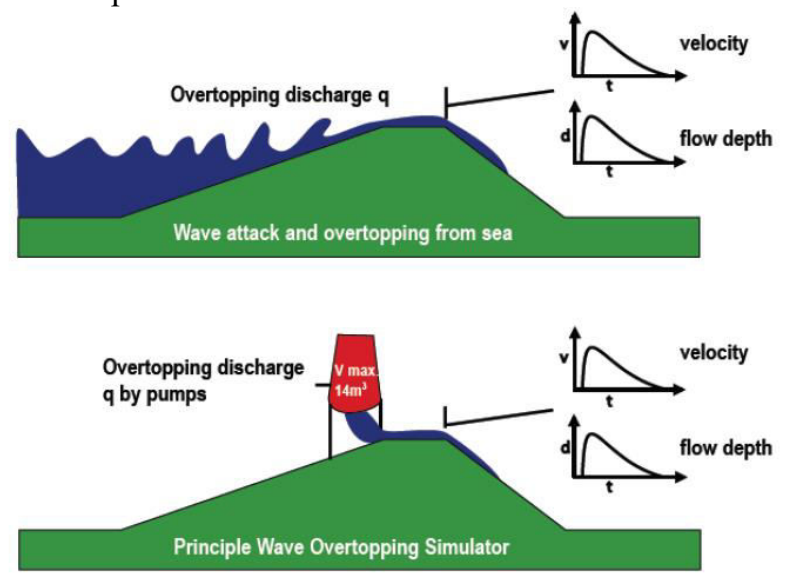

Figure 1. Principles of the wave overtopping simulator (from:[5]).

The released overtopping volumes represent irregular waves. The amount of overtopping waves and volumes depend on the representative wave conditions and the geometry of the outer side of the dike. The experiment in Millingen aan de Rijn was performed for a significant wave height and period of $1.0 \mathrm{~m}$ and $4 \mathrm{~s}$, respectively and an outer slope of 1:3 [12].

The wave overtopping simulator was located at the crest of the dike, 1.5 meters from the edge of the asphalt pavement (Fig. 2). The road section had a width of 3.1 meters. Both berms were damaged due to traffic over a distance of 0.5 meters. The inner crest of the dike was located 1.4 meters from the edge of the asphalt pavement. The first steep part of the inner slope had an average slope of 1:3. The second part of the slope was less steep with a gradient of $1: 6$, resulting in a smooth transition from the slope to the toe. During the overtopping experiment in Millingen aan de Rijn the largest erosion was observed at the crest. Little erosion was observed along the slope and at the dike toe [12].

The wave overtopping simulator represents the boundary conditions for the hydrodynamic model described in section 3. In order to validate the hydrodynamic model two datasets are used. The first dataset consists of the measurement of flow velocity and water depth in Millingen aan de Rijn. In this experiment no erosion occurred, because the dike was covered with geotextile. These data are used to validate the hydrodynamic conditions along the slope of the dike $\left(\mathrm{SM}_{4}\right.$ in Fig. 2). For the second data set without geotextile, no hydrodynamic measurements were carried out, only the dike profiles were measured. Therefore, we use this dataset to validate the computed erosion of the coupled hydrodynamic-erosion model.

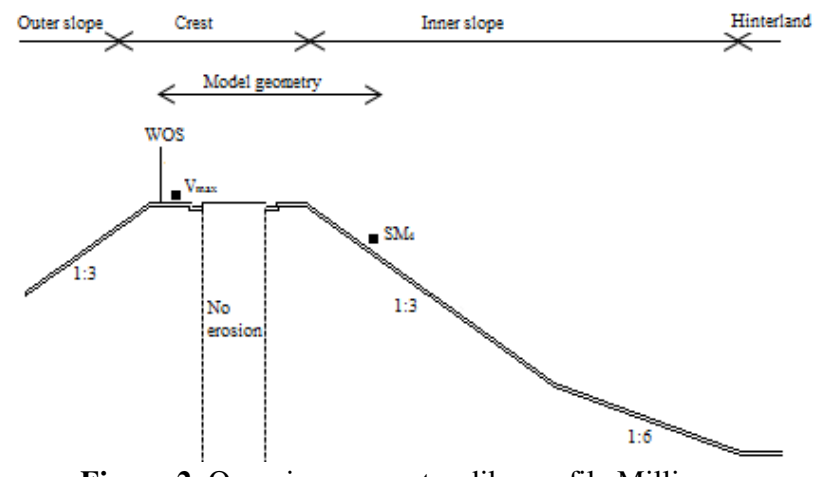

Figure 2. Overview geometry dike profile Millingen aan de Rijn. WOS indicates the location of the Wave overtopping simulator, $\mathrm{V}_{\max }$ the location of the simulator outlet and $\mathrm{SM}_{4}$ the location of the validation data measurements.

The dike profile has a grass cover of $10 \mathrm{~cm}$ with underneath a homogeneous clay core.

\section{Coupled hydrodynamic-erosion model}

The amount of scour due to wave overtopping is computed with a coupled hydrodynamic-erosion model (Fig. 3). This model consists of a CFD simulation to compute the bed shear stresses which are then used to compute the amount of scour. The study focuses on the crest of the dike, and therefore the model domain only includes the crest and a small part of the inner slope (Fig. 2 ). The eroded dike profiles are obtained by subtracting the computed scour depth from the initial dike profile. After updating the dike profile the CFD simulation is run again to compute the shear stresses after erosion. It is assumed that the grass cover is completely eroded when the erosion depth is larger than 0.1 meters [13]. The roughness at these locations are then adapted to a value that corresponds with clay (Table 1).

An overtopping discharge of $0.05 \mathrm{~m}^{3} / \mathrm{s} / \mathrm{m}$ is simulated up to a duration of three hours, corresponding with approximately 1500 waves. The erosion that evolves due to a single overtopping wave is relatively small and for this reason it was not necessary to simulate each overtopping wave with an updated dike profile. The dike profile is updated after circa 500 waves, which corresponds with one hour of testing in Millingen aan de Rijn for a discharge of $0.05 \mathrm{~m}^{3} / \mathrm{s} / \mathrm{m}$.

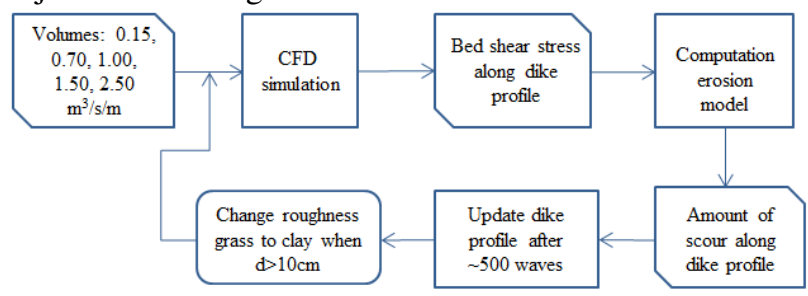

Figure 3. Steps of the coupled hydrodynamic-erosion model. 


\subsection{CFD Simulation}

The CFD simulation is performed with COMSOL Multiphysics [14] using a two dimensional unsteady model. The CFD simulation solves the ReynoldsAveraged Navier-Stokes (RANS) equations with a k- $\varepsilon$ turbulence model. The values of dimensionless constants $\mathrm{C} 1=1.44, \mathrm{C} 2=1.92, \mathrm{C} \mu=0.09, \sigma \epsilon=1.3$ and $\sigma \mathrm{k}=1$ in the $\mathrm{k}-\varepsilon$ model are taken from [15]. The two phase flow method is used to track the interface between water and air.

The wave overtopping simulator is included in the model domain to be able to simulate the different overtopping volumes (Fig. 4). No data of the flow velocities and water depths over time at the outlet of the simulator are available, only the maximum velocity was recorded. Therefore, we use the volumes as input and validate maximum flow velocity at the simulator outlet, and water depths and flow velocities at the inner slope. Gravity is included as a pressure distribution along the model domain. Wall functions are applied along the overtopping simulator, the road and the dike slope to account for the roughness of the different materials. The roughness of clay is based on the normal value given by [16]. The roughness of steel is determined by calibration on the maximum flow velocities at the simulator outlet and corresponds with the maximum value given by [16]. The roughness of the grass and asphalt sections were measured during the experiment in Millingen aan de Rijn [17]. Inlet and outlets are located at the remaining model boundaries (Fig. 4).

\begin{tabular}{|c|c|}
\hline Material & $\begin{array}{c}\text { Nikuradse } \\
\text { roughness } \\
\text { height [m] }\end{array}$ \\
\hline Grass & $6.8 \times 10^{-2}$ \\
\hline Clay & $2.1 \times 10^{-3}$ \\
\hline Asphalt & $4.7 \times 10^{-3}$ \\
\hline Steel & $6.8 \times 10^{-3}$ \\
\hline
\end{tabular}

Table 1. Roughness of the different materials

The simulation uses the finite element method to solve the governing equations numerically. The grid size decreases in downward direction to obtain a high accuracy near the surface of the dike profile, where the bed shear stresses are computed.

At the inner slope of the dike profile, the velocities increase resulting in lower water depths. Therefore, a finer mesh is needed to capture the hydrodynamic conditions on the steep slope. To provide this, a boundary layer with quadrilateral elements is defined along the inner dike slope that consisted of three cells of $2.3 \mathrm{~mm}$ each. Quadrilateral mesh elements capture the flow conditions more accurately, because the flow is parallel to the bottom of the slope and almost no changes in normal direction are expected.

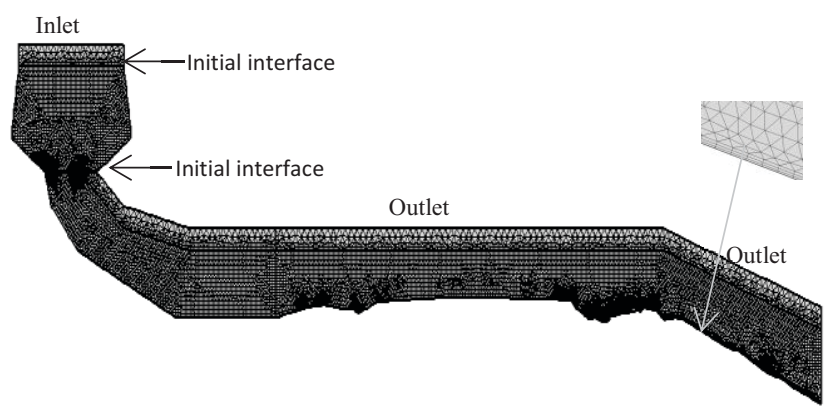

Figure 4. Mesh and boundary conditions CFD simulation.

\subsection{Erosion model}

The turf-element model of [18] is used to compute the amount of scour. In this model the amount of scour is computed as a function of maximum velocity. This is adapted to a function dependent on the shear stresses. [19] showed the importance of including overtopping duration and the effect of using intermittent wave overtopping for the computation of dike erosion. Therefore we adjust the turf-element model to a time dependent formulae. The amount of scour is computed throughout the simulation based on the actual bed shear stress as suggested by [20].

The turf-element model is only applicable for an erosion depth smaller than 0.1 meters. [21] extended this model for greater depths by implementing a depthdependency factor for the strength and load terms. Therefore, it is not restricted to scour of the grass cover only. Erosion evolves when the bed shear stress exceeds the critical bed shear stress. The erosion model is given by:

$$
y_{n}=\sum_{i=1}^{I} \frac{\left(\omega^{2} \frac{\tau_{i}+\tau_{i+1}}{2}-\tau_{c}(d)\right) \times \Delta t}{E_{\text {soil }}(d)}
$$

Where $y_{n}$ represents the amount of scour per time step $[\mathrm{m}], \omega$ the turbulence coefficient [-], $\tau_{i}$ the bed shear stress obtained with the CFD simulation [N/m2], and $\tau_{c}$ and $E_{\text {soil }}$ the critical bed shear stress $[\mathrm{N} / \mathrm{m} 2]$ and a soil parameter [-] respectively both as a function of depth, and $\Delta t$ the time step. The total scour during a single wave is computed by a summation of the amount of scour per time step:

$$
Y=\sum_{n=1}^{N} y_{n}
$$

The strength terms $\tau_{c}$ and $E_{\text {soil }}$ are adapted to the situation of the validation data. The model assumes a clay and grass strength dependent of the depth (d) (Fig. 5). At the surface the strength is dominated by the grass cover. We assume that the strength decreases exponentially with depth and the strength of the clay cohesion increases linearly with depth.

The model assumes a grass sod with a depth of 0.1 meters based on the work of [18]. Horizontal variations of the grass strength are neglected. Underneath the grass cover a homogeneous clay core is present. Erosion development underneath the road section is not considered in this paper (Fig. 2), although significant undermining of the road was observed in the field experiment. Deposition is not included in the model. It is 
assumed that all eroded particles are transported out of the model domain, which is feasible given the high flow velocities and deposition was only observed downstream of the dike toe (which is beyond the model domain).

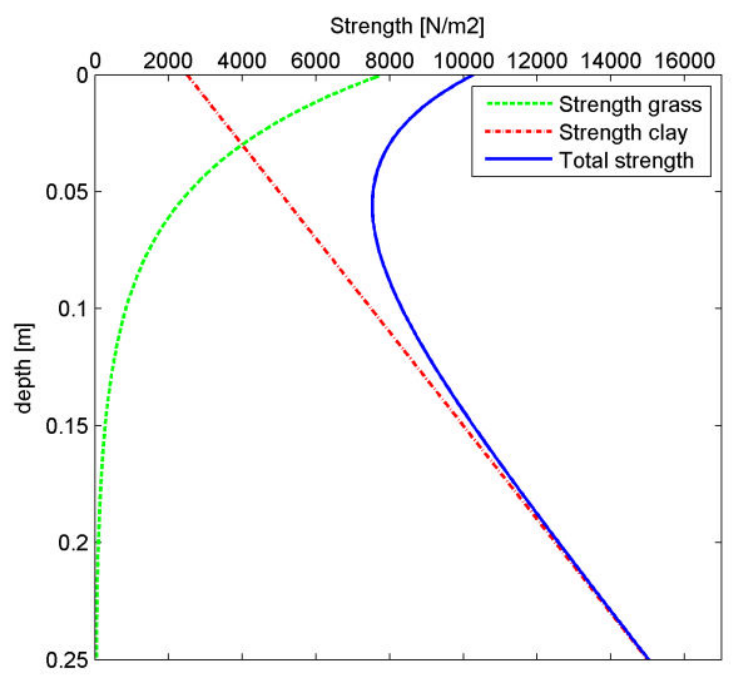

Figure 5. Grass and clay strength as a function of depth.

\subsection{Cases}

In this study four cases are investigated:

Case 1: Validation of the hydrodynamics. To be able to validate the hydrodynamics the test set up of the erosion measurements in Millingen aan de Rijn is used (Fig. 2). Wave volumes of 0.15, 0.40, 0.70, 1.00, 1.50 and $2.50 \mathrm{~m}^{3} / \mathrm{m}$ are simulated. The results are compared with the hydraulic measurements performed during the wave overtopping experiment in Millingen aan de Rijn.

Case 2: Validation of erosion model. The geometry and structure are equal to case 1 . The 0.05 $\mathrm{m}^{3} / \mathrm{s} / \mathrm{m}$ discharge up to a duration of three hours is simulated. The dike profile is updated after one hour of testing based on the computed erosion. The simulated dike profiles are compared with the observed profiles during the experiment in Millingen aan de Rijn.

Case 3: Effect of a road. The geometry and structure are equal to case 1 , except the roughness of the road section is changed to a value corresponding with grass to represent a dike without a road. The erosion caused by 100 overtopping waves with a volume of $1.50 \mathrm{~m}^{3} / \mathrm{m}$ is computed, which is used for updating the dike profile. This process is repeated three times in order to simulate erosion caused by 300 overtopping waves.

Case 4: Effect of irregularities in the dike profile. The damaged shoulders of the road section in the geometry of case 1 are filled up, leading to a smoother dike profile. The dike crest is only covered with grass. The erosion caused by 100 overtopping waves with a volume of $1.50 \mathrm{~m}^{3} / \mathrm{m}$ is computed, which is used for updating the dike profile. This process is repeated three times in order to simulate erosion caused by 300 overtopping waves.

\section{Results}

\subsection{Case 1: Hydrodynamic validation}

The validation is carried out on the velocities $\mathrm{v}_{\max }$, overtopping times and water depths at the simulator outlet and on velocities $\mathrm{v}_{\mathrm{sm} 4}$ and water depths at location $\mathrm{SM}_{4}$ on the inner slope (Fig. 2).

The simulated maximum velocities deviate less than $30 \%$ of the measured maximum velocities for all wave volumes (Table 2). The maximum water depths at the simulator outlet are accurate, especially for the large overtopping volumes. They are slightly underestimated for the 0.15 and $0.40 \mathrm{~m}^{3} / \mathrm{m}$ volumes. Additionally, the simulated overtopping time at the simulator outlet is only out of range for the $0.15 \mathrm{~m}^{3} / \mathrm{m}$ volume. So, for the 0.15 $\mathrm{m}^{3} / \mathrm{s}$ volume the depth is underestimated and consequently the overtopping time is overestimated, showing that the overtopping tongue is too stretched.

The simulated maximum velocities at SM4 deviate between $-0.4 \%$ and $+14.0 \%$ from the measured velocities (Table 3). Simulation velocities accurately is of great importance since flow velocities are a determinant of erosion development. The validation results show that maximum velocities at SM4 are in good agreement with measurements. Water depths show larger deviations, especially for the smaller overtopping volumes. The simulated water depths are between $12 \%$ and $59 \%$ higher than measured water depths. During the field measurements of the hydraulic experiment, geotextile was located along the dike crest. In the simulation, the damaged transition gaps lead to a decrease of the flow velocities of the first part of the overtopping tongue. This temporarily obstruction of the flow results in higher maximum water depths along the slope. The water depth of the $2.50 \mathrm{~m} 3 / \mathrm{m}$ wave is better predicted compared to the smaller overtopping volumes. This indicates that the transition gaps mainly influence hydrodynamic conditions of small overtopping volumes.

\begin{tabular}{|c|c|c|c|c|c|c|}
\hline & \multicolumn{6}{|c|}{ Volume $\left[\mathrm{m}^{3} / \mathrm{m}\right]$} \\
\hline & 0.15 & 0.40 & 0.70 & 1.00 & 1.50 & 2.50 \\
\hline $\begin{array}{l}\mathrm{v}_{\max }[\mathrm{m} / \mathrm{s}] \\
\text { measured }\end{array}$ & 2.95 & 3.43 & 4.10 & 4.62 & 4.84 & 6.47 \\
\hline $\begin{array}{l}\mathrm{v}_{\max }[\mathrm{m} / \mathrm{s}] \\
\text { simulated }\end{array}$ & 3.05 & 3.01 & 3.57 & 3.76 & 4.11 & 4.65 \\
\hline $\begin{array}{c}\text { Difference } \\
{[\%]^{*}}\end{array}$ & +3 & -12 & -13 & -19 & -15 & -28 \\
\hline $\begin{array}{c}\mathrm{h}_{\max }[\mathrm{m}] \\
\text { measured }\end{array}$ & 0.10 & 0.13 & 0.15 & 0.18 & 0.20 & 0.26 \\
\hline $\begin{array}{c}\mathrm{h}_{\max }[\mathrm{m}] \\
\text { simulated }\end{array}$ & 0.05 & 0.10 & 0.14 & 0.16 & 0.19 & 0.22 \\
\hline $\begin{array}{c}\text { Difference } \\
{[\%]}\end{array}$ & -50 & -23 & -7 & -11 & -5 & -15 \\
\hline $\begin{array}{c}\mathrm{T}_{\text {ovt }}[\mathrm{s}] \\
\text { measured }\end{array}$ & 1.48 & 2.05 & 2.38 & 2.78 & 3.40 & 4.24 \\
\hline $\begin{array}{c}\mathrm{T}_{\text {ovt }}[\mathrm{s}] \\
\text { simulated }\end{array}$ & 2.40 & 2.35 & 2.60 & 2.90 & 3.10 & 4.00 \\
\hline $\begin{array}{c}\text { Difference } \\
{[\%]}\end{array}$ & +62 & +15 & +9 & +4 & -9 & -6 \\
\hline
\end{tabular}

Table 2. Validation CFD simulation at simulator outlet. * Percentage difference of the simulated water depth, compared to the average of the two measured values. 


\begin{tabular}{|c|c|c|c|c|}
\hline & \multicolumn{4}{|c|}{ Volume $\left[\mathbf{m}^{3} / \mathbf{m}\right]$} \\
\cline { 2 - 5 } & $\mathbf{0 . 4 0}$ & $\mathbf{1 . 0 0}$ & $\mathbf{1 . 5 0}$ & $\mathbf{2 . 5 0}$ \\
\hline $\mathrm{v}_{\mathrm{SM} 4}[\mathrm{~m} / \mathrm{s}]$ measured & 4.45 & 5.13 & 5.62 & 5.60 \\
\hline $\mathrm{v}_{\mathrm{SM} 4}[\mathrm{~m} / \mathrm{s}]$ simulated & 4.43 & 5.12 & 5.57 & 6.38 \\
\hline Difference [\%]* & -0.4 & -0.3 & -0.8 & +14 \\
\hline $\mathrm{h}_{\mathrm{SM} 4}[\mathrm{~m}]$ measured & 0.02 & 0.06 & 0.10 & 0.16 \\
\hline $\mathrm{h}_{\mathrm{SM} 4}[\mathrm{~m}]$ simulated & 0.03 & 0.10 & 0.13 & 0.18 \\
\hline Difference [\%] & +51 & +59 & +42 & +12 \\
\hline
\end{tabular}

Table 3. Validation CFD simulation at $\mathrm{SM}_{4}$.

* Percentage difference of the simulated water depth, compared to the average of the two measured values.

To get confidence in the simulated shear stresses, the maximum bed shear stresses along the dike profile are plotted for the different overtopping volumes. Fig. 6 shows that the maximum shear stresses at the road section are relatively small compared to the shear stresses along the grass cover. This corresponds with the low roughness of the asphalt layer. In addition, peaks of the bed shear stresses are present at locations at which irregularities in the dike profile occur with a relatively steep upward slope. The upward slope obstructs the flow, leading to deceleration and therefore to a significant increase of the bed shear stresses. Similarly, Fig. 6 shows that higher shear stresses occur for larger overtopping volumes.

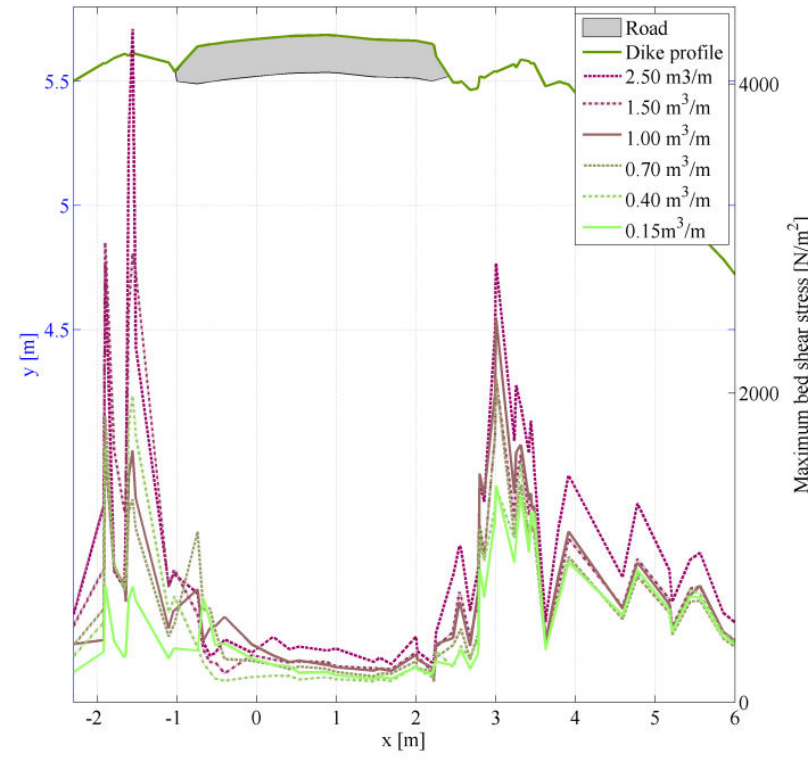

Figure 6. Simulated maximum shear stresses due to overtopping wave volumes of $0.40,0.70,1.00,1.50$ and $2.50 \mathrm{~m} 3 / \mathrm{m}$

During wave overtopping the flow is highly turbulent and the surface is not smooth [5]. Furthermore, the flow velocities near the bed are lower than at the surface due to bottom friction. Both elements are included in the model results (Fig. 7).
The validation results show that the velocities and water depths are simulated accurately and the velocity profile and the bed shear stress distribution follow a realistic pattern. Differences between measurements and simulated outcomes can be explained by differences in the test set up. Despite these differences, the validation results give enough confidence in an accurate representation of the hydrodynamic processes in the CFD model.

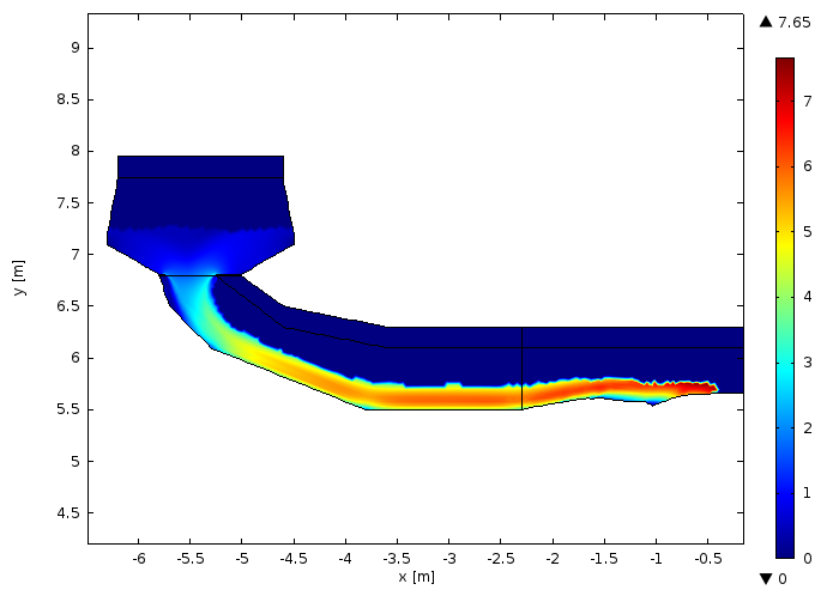

Figure 7. Flow velocities of the overtopping tongue at time $\mathrm{t}=1.5 \mathrm{~s}$.

\subsection{Case 2: Erosion validation}

The validation of the erosion model focusses on the landside transition of the asphalt with the grass cover. The model was set up to compute the erosion onset. Therefore, the validation is performed after three hours of testing with a discharge of $0.05 \mathrm{~m}^{3} / \mathrm{s} / \mathrm{m}$ which represents approximately 1500 waves (Fig. 8). The root mean square error (RMSE) of the measured and simulated profiles at the landside transition between $x=2$ and $x=3.5$ after three hours of testing is equal to 0.038 meters.

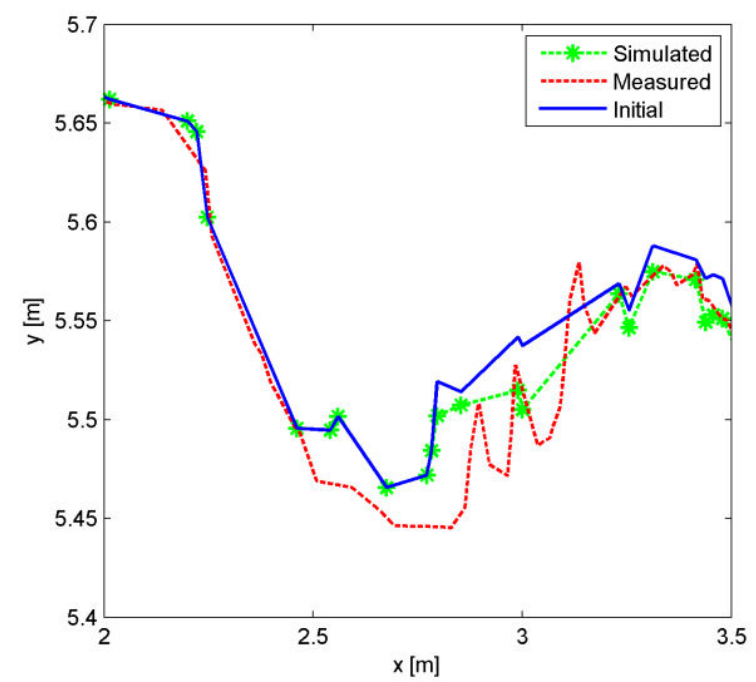

Figure 8. Measured and simulated dike profile after three hours of $0.05 \mathrm{~m}^{3} / \mathrm{s} / \mathrm{m}$ test and initial profile.

The simulated erosion depths show moderate agreement with the measured erosion depths. The 
location and order of magnitude of this erosion onset is modelled quite accurately. However, the measured eroded profile shows a more irregular pattern. The RMSE of the measured and simulated erosion depths increases during the overtopping experiment. In the observations the grass cover is folded before it is teared off, leading to a temporarily increase of the dike profile at these locations. This process is not considered during the simulation and leads to temporal random variations between the observations and simulation. However, this has little effect on the long term. We correctly predict the location and average depth of the large scale erosion, but the model is not able to simulate the small scale variations.

It can be concluded that the erosion model is capable of predicting the location of the large scale scour correctly and it simulates erosion depths of the same order of magnitude as was measured during the experiment. Additionally, the simulated dike profiles show realistic behaviour. These validation results give enough confidence of the accuracy of the erosion model.

\subsection{Case 3: Effect of a road}

The grass cover has a higher roughness than the asphalt road structure, which leads to a change in the hydrodynamics. Therefore, the erosion onset at the crest for a bare grass covered dike profile changes compared to a dike with a road located at the crest. Fig. 9 shows the erosion depths of the landside transition after 300 waves with a volume of $1.50 \mathrm{~m}^{3} / \mathrm{m}$. The simulation shows that erosion decreases due to the absence of the road. The higher roughness coefficient of the grass cover leads to more energy dissipation and the overtopping tongue is more slowed down. This results in a decrease of the bed shear stresses and therefore to a decrease in the amount of scour. Additionally, the simulated turbulence of the flow is lower for the bare grass covered dike than for the dike profile with a road located at the crest. Due to the sudden increase of the bed roughness, caused by the transition of the asphalt layer with the grass cover, higher bed shear stresses evolve [11].

These results show that the roughness of the road section leads to higher erosion at the landside transition compared to grass covered dike profile. Energy loss is focussed in one location, resulting in deeper scour holes. However, the increase in erosion due to an asphalt layer is relatively small as it only increases the maximum scour depth by $14 \%$.
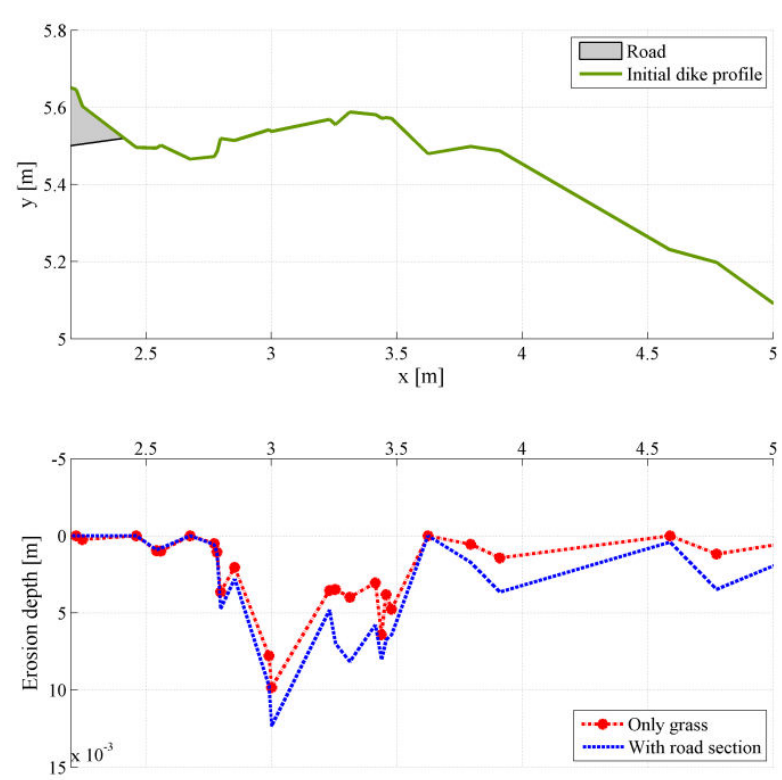

Figure 9. Erosion depths of landside transition for an irregular dike profile with and without a road on top after 300 waves with a volume of $1.50 \mathrm{~m}^{3} / \mathrm{m}$.

\subsection{Case 4: Effect of irregularities in the dike profile}

During wave overtopping less erosion is predicted for the smoothed grass covered dike profile compared to the irregular dike profile with a road located at the crest (Fig. 10). The decrease of scour in front of the road section is mainly caused by the absence of irregularities in the dike profile. An irregularity, with an upward slope, leads to energy loss and to a sudden increase of the shear stresses which are substantially larger than the critical bed shear stress. The decrease of scour at the landside transition is caused by the combination of higher roughness of the grass cover compared to the asphalt layer and the absence of irregularities. Due to the higher roughness, the flow velocities are lower leading to lower shear stresses compared to a dike crest with a road on top. Furthermore, a smooth dike profile with the absence of irregularities leads to a decrease of the bed shear stress.

Along the upper part of the slope of the dike profile $(x>4)$, erosion evolves for the smooth dike profile while no erosion is present for the dike profile with a road on top. The damaged shoulders of the road section lead to loss of energy and therefore to lower flow velocities along the dike slope. For the smooth dike profile more energy is conserved leading to higher velocities along the dike slope and therefore to higher shear stresses. As a result the location of erosion shifts from the crest to the slope. 

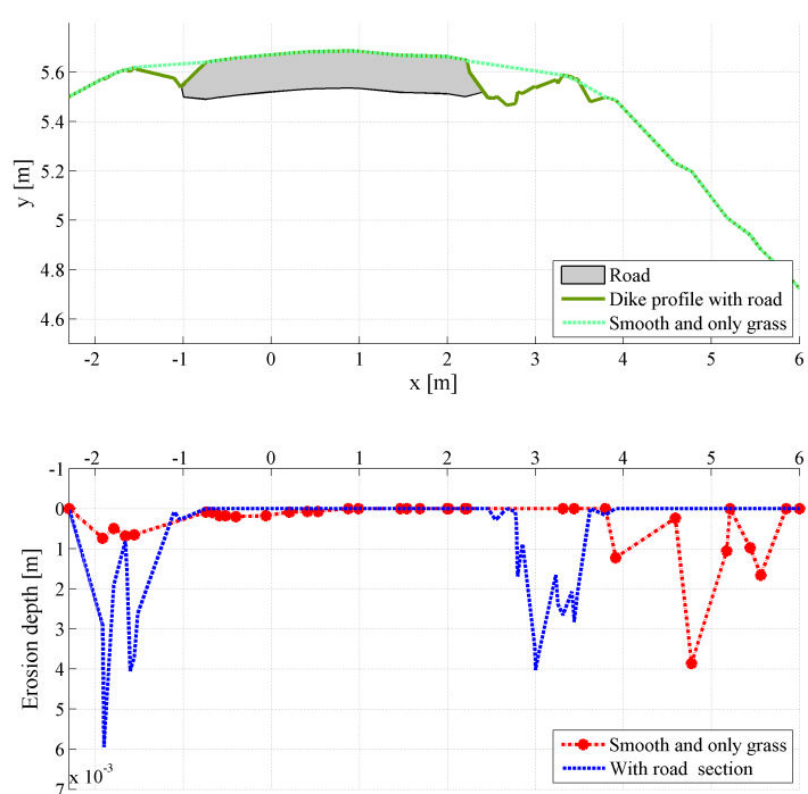

Figure 10. Erosion depths for a smooth dike profile and an irregular dike profile with a road on top after 150 waves with a volume of $1.50 \mathrm{~m}^{3} / \mathrm{m}$.

\section{Discussion}

We only simulated the onset of erosion. Literature (e.g. [9]) showed that erosion typically develops into breaching of dikes at the location of initial erosion due to headcut. Our model was not designed to model dike breach and therefore the simulation has to be stopped when erosion is of such an extent that dike breach can be expected.

The turf-element model of [18] was used, extended with a depth and time dependency as suggested by [21] and [20]. Therefore, erosion was computed based on shear stresses that evolve in time. This leads to a more detailed erosion model than used in literature so far. However, the soil parameter $\mathrm{E}_{\text {soil }}$ was determined for the case in which the amount of erosion is computed based on the maximum shear stress. This parameter was not adjusted for a time dependent formulae, which may lead to slightly overestimation or underestimation of the scour development.

[4] and [22] found that most erosion due to wave overtopping evolves at the toe of the dike. In this study erosion developed at the crest of the dike. In the modelling studies of [4] and [22] relatively smooth dike profiles were investigated. Additionally, during other experiments performed with the wave overtopping simulator it was found that for a grass covered dike without a road most erosion evolves at the toe of the dike [23]. We showed that the irregular profile caused by the damaged shoulders of the road section as well as the increased turbulence due to a change in roughness may be the cause of the erosion development at the crest. A preliminary simulation with our model including the dike toe showed that due to the increasing amount of scour at the crest, the erosion at the toe decreased. This implies that the location of the initiation of scour due to wave overtopping shifts from the toe to the crest, which affects breach development. Further study is needed to determine which scour location is most vulnerable to dike failure. In addition, we recommend to investigate the effect of the location of scour on the interaction with other failure mechanisms in a future study.

[24] concluded that three-dimensional modelling is an essential requirement for accurate modelling of dike breach. In this study a two-dimensional model was developed. This study focussed only on the onset of erosion development and therefore it was assumed that the results were accurate enough for the scope of this study. The onset of erosion is a $2 \mathrm{D}$ process where horizontal variation is not dominant compared to dike breach, where the development of the breach width is an essential component. However, in 2D the effect of submerged objects can be simulated.

\section{Conclusions}

The coupled hydrodynamic-erosion model was used to investigate the influence of a road located at the crest of a dike on the location and magnitude of the erosion. Four cases were studied. The validation of the hydrodynamics and the scour depths showed agreement with the measurements performed during the wave overtopping experiment in Millingen aan de Rijn. This showed that the model was capable to model the coupled hydrodynamic-dike structure system.

It was concluded that an asphalt road structure leads to more erosion development at the crest of the dike profile compared to a bare grass covered dike profile. The decrease in roughness due to a road leads to more erosion at the landside transition caused by higher flow velocities and increased turbulence. Furthermore, irregularities at the road shoulders lead to more erosion. So from the model results, it is expected that a road located at the crest of a dike causes a shift of the maximum erosion from the slope and toe of the dike to the crest.

\section{Acknowledgement}

This research is supported by the Dutch Technology Foundation STW, which is part of the Netherlands Organisation for Scientific Research (NWO), and which is partly funded by the Ministry of Economic Affairs. The authors would like to thank Gosse-Jan Steendam from INFRAM, Andre van Hoven from Deltares and Jentsje van der Meer from Van der Meer Consulting B.V. for providing the data.

\section{References}

[1] Kok M., Vrijling J. K. and Zevenbergen C. (2013). Towards an integrated evaluation framework for Multi-Functional Flood Defences. Londen, ISBN: 978-0-415-62144-1: Taylor \& Francis Group.

[2] CIRIA. (2013). The International Levee Handbook. London, ISBN 978-0-86017-734-0: CIRIA, Griffin Court.

[3] Wu W. (2011). Earthen Embankment Breaching. 
J. Hydraul. Eng., vol. 137, no. 12, pp. 15491564.

[4] Bhattarai P. K., Nakagawa H., Kawaike K. and Zhang H. (2015). Study of breach characteristics and scour pattern for overtopping induced river dyke breach. E-roceedings of the 36th IAHR World Congress, pp. 1-11.

[5] Van der Meer J. W., Schrijver R., Hardeman B., Van Hoven A., Verheij H. and Steendam G. J. (2009). Guidance on erosion resistance of inner slopes of dikes from three years of testing with the Wave Overtopping Simulator. Proc. ICE 2009, no. 1994, pp. 1-14, ISBN: 9780727741318.

[6] Hanson G. J., Cook K. R. and Hunt S. L. (2005) Physical modeling of overtopping erosion and breach formation of cohesive embankments. Trans, ASABE, vol. 48, no. 5, pp. 1783-1794, 2005.

[7] Van Hoven A., Hardeman B., Van der Meer J. W. and Steendam G. J. (2010). Sliding stability of landward slope clay cover layers of sea dikes subject to wave overtopping. Proc. ICCE, p. 12.

[8] Oumeraci H., D'Eliso C. and Kortenhaus A. (2005). Breaching of coastal dikes : state of the art. Braunschweig, LWI Report number: 910.

[9] Zhu Y. (2006). Breach Growth in Clay-Dikes. Technical University Delft, ISBN: 9789090209647.

[10] Steendam G. J., Van Hoven A., Van der Meer J. W. and Hoffmans G. (2014) Wave Overtopping Simulator tests on transitions and obstacles at grass covred slopes of dikes. ASCE, Proc. ICCE 2014. pp. 1-14.

[11] Morris M. (2012). WP 3 : Reliability of Urban Flood Defences - D.3.1 Guidance on improved performance of urban flood defences, Report number: WP3-01-12-11.

[12] Bakker J., Melis R. and Mom R. (2013). Factual Report: Overslagproeven Rivierenland. INFRAM, Project number: 12i071, Version 1.0, Marknesse.

[13] Hoffmans G., Akkerman G. J., Verheij H., Van Hoven A. and Van der Meer J. W. (2008). The erodibility of grassed inner dike slopes against wave overtopping. ASCE, Proc. ICCE 2008, Hamburg., pp. 3224-3236.

[14] COMSOL bv. (2012). Comsol Multiphysics User's Guide version 4.3. ISBN: 1781273332.

[15] Launder B., Morse A., Rodi W. and Spalding D. (1972). The prediction of free shear flows - A comparison of the performance of six turbulent models. Proceedings of NASA Conference on Free Shear Flows.

[16] Chow V. T. (1959). Open-Channel Hydraulics. New York, ISBN: 07-010776-9: McGraw-Hill Book Company, Inc.

[17] Van Hoven A., Verheij H., Hoffmans G., and Van der Meer J. W. (2013). Evaluation and Model Development: Grass Erosion Test at the Rhine dike, Delft, Project number: 1207811-002.
Turbulence on Soil Erosion. Delft: Eburon Academic Publishers.

[19] Dean R. G., Rosati J. D., Walton T. L. and Edge B. L. (2010). Erosional equivalences of levees: Steady and intermittent wave overtopping. Ocean Eng., vol. 37, no. 1, pp. 104-113.

[20] Partheniades E. (1965). Erosion and deposition of cohesive soils. J. Hydraul. Div., vol. 91, no. 1, pp. 105-139.

[21] Valk A. (2009). Wave overtopping impact of water jets on grassed inner slope transitions. TU Delft, retrieved from:

http://repository.tudelft.nl/view/ir/uuid:5ca03ac70296-4ccd-b7b0-e9485cfc934f/.

[22] Pan Y., Li L., Amini F. and Kuang C. (2012). Overtopping erosion and failure mechanism of earthen levee strengthened by vegetated HPTRM system. Ocean Eng., vol. 96, pp. 139-148.

[23] Van der Meer J. W., Hardeman B., Steendam G. J., Schüttrumpf H. and Verheij H. (2010). Flow depths and velocities at crest and landword slope of a dike, in theory and with the wave overtopping simulator. Proc. ICCE 2010.

[24] Sabbagh-Yazdi S. and Jamshidi M. (2012). Depth-Averaged Hydrodynamic Model for Gradual Breaching of Embankment Dams Attributable to Overtopping Considering Suspended Sediment Transport. J. Hydraul. Eng., pp. 580-592. 